\title{
Analysis on Calcination of Cementitious Powder of Waste Concrete for Raw Cement
}

\author{
Park, Dong-Cheon ${ }^{1 *} \quad$ Kwon, Eun-Hee ${ }^{1} \quad$ Ahn Jae-cheol ${ }^{2}$ \\ Department of Architectural Engineering, Korea Maritime and Ocean University, Youngdo-Gu, Busan, \\ 606-791, Korea ${ }^{1}$ \\ Graduate School, Dong-A University, Saha-Gu, Busan, 602-714, Korea ${ }^{2}$
}

\begin{abstract}
The purpose of this study is to examine whether cementitious powder separated from waste concrete can be used as an alternative raw material to limestone and reduce the usage of natural resource (limestone) and $\mathrm{CO}_{2}$ emission based on recycling cementitious powder from waste concrete. Experiments actually analyzed the chemical composition of cementitious powder and performed hyperthermia analysis, measurement of free $\mathrm{CaO}$ and $\mathrm{XRD}$ analysis to measure the degree of recovery of hydration in the model of cementitious powder manufactured based on chemical composition. These were performed in each cementitious powder model at different calcination temperatures such as $900^{\circ} \mathrm{C}, 1200^{\circ} \mathrm{C}$, $1300^{\circ} \mathrm{C}, 1400^{\circ} \mathrm{C}$ and $1450^{\circ} \mathrm{C}$. Through the experiments, it was found that the recovery of hydration was at a level which can be used as the alternative raw material for limestone, but the replacement ratio was directly affected by the degree of mixing of fine aggregate in less than $150 \mu \mathrm{m}$, which cannot be separated from cementitious powder. It was shown that there was no difference in the production of compounds involved in hydration at calcination temperatures of $1200^{\circ} \mathrm{C}$ or higher. Therefore, to pursue the replacement of limestone and reduction of greenhouse gas by recycling cementitious powder, the development of technology to efficiently separate aggregate fine powder is required.
\end{abstract}

Keywords : cementitious powder of waste concrete, recycled cement, powder of fine

\section{Introduction}

Measures for recycling waste concrete, which accounts for more than $60 \%$ of construction waste, are actively being studied these days in order to minimize the environmental load occurring in construction and in the construction process of eco-friendly structures. Through this process, the study reaches the practical stage to manufacture and reuse cyclic aggregate with high quality through a

Received : October 4, 2013

Revision received : December 31, 2013

Accepted : January 6, 2014

* Corresponding author : Park, Dong-Cheon

[Tel: 82-10-5533-9443, E-mail: dcpark@kmou.ac.kr]

(c)2014 The Korea Institute of Building Construction, All rights reserved. variety of recycling processes[1,2]. In addition, some studies to recycle the fine grain containing fine aggregate produced after manufacturing cyclic aggregate and the cementitious powder of paste ingredients in which fine aggregate ingredients are removed are being conducted. In such cases of recycling cementitious powder it was generally used as an alternative for silica flour in the manufacture of cement series products such as roadbed ash as inert filler or brick. Some studies are being conducted with the goal of utilizing recycled cement through low-temperature calcination process $[3,4]$.

The amount of $\mathrm{CO}_{2}$ emission depending on decarbonation of limestone compared with the total $\mathrm{CO}_{2}$ emission was $67.5 \%$. The amount of $\mathrm{CO}_{2}$ emission depending on combustion was $26.7 \%$ and $\mathrm{CO}_{2}$ emission 
depending on electric power in plants was $5.8 \%$. Therefore, it was evaluated to be very significant in the reduction of greenhouse gas.

In this study, we would like to use the large amount of paste ingredients included in cementitious powder of waste concrete (consists of cement hydrate in which coarse aggregate and fine aggregate more than 150 um are removed through recycling process of waste cement, and some fine aggregate cementitious powder; hereinafter, called waste cementitious powder) as an alternative raw material to limestone.

In this case, it is expected to have the effect of saving natural resources as a substitute for limestone, and reduce the greenhouse gas emissions caused by decarbonation reaction of limestone, according to the mechanism for hydration reaction of cement and recycled cement as shown in equations (1), (2) and (3).

Thus, this study analyzed the possibility of the use of waste cementitious powder mixed with cementitious powder of fine aggregate as raw material (Limestone) for cement through the optimal combination of cement raw material. In addition, we analyzed the possibility of saving limestone raw material through this process[5].

Manufacture of cement $: \mathrm{CaCO}_{3} \stackrel{\text { Heat }}{\rightarrow} \mathrm{CaO}+\mathrm{CO}_{2}----(1)$

Hydration of cement $: \mathrm{CaO}+\mathrm{H}_{2} \mathrm{O} \stackrel{\text { Heat }}{\rightarrow} \mathrm{Ca}(\mathrm{OH})_{2}+\mathrm{H}_{2} \mathrm{O}--(2)$

Manufacture of re-cement $: \mathrm{Ca}(\mathrm{OH})_{2} \stackrel{\text { Heat }}{\rightarrow} \mathrm{CaO}+\mathrm{H}_{2} \mathrm{O}--(3)$

\section{Materials used}

This study manufactured model waste cementitious powder and used it as raw material for experiment based on the chemical compositions of actual waste cementitious powder. Since formulation and age of waste cementitious powder in each site were unknown and these values were not consistent, it was determined to be inappropriate for a comparative analysis on the addition ratio of fine aggregate and calcination temperature. The model waste cementitious powder used paste aged 6 months and fine aggregate less than $150 \mu \mathrm{m}$ based on previous studies. In addition, converter slag, which has high iron content, was used to coordinate IM as an ingredient adjuster. Chemical compositions of the model waste cementitious powder and byproduct raw materials used in this study are shown in Tables 1 and 2 .

Table 1. Chemical compositions of model waste cementitious powder

\begin{tabular}{cccccc}
\hline Classification & $\mathrm{CaO}$ & $\mathrm{SiO}_{2}$ & $\mathrm{Al}_{2} \mathrm{O}_{3}$ & $\mathrm{Fe}_{2} \mathrm{O}_{3}$ & $\mathrm{SO}_{3}$ \\
\hline Paste & 47.70 & 18.20 & 3.86 & 2.63 & 0.00 \\
Fine aggregate & 1.32 & 75.10 & 12.10 & 2.03 & 0.00 \\
\hline
\end{tabular}

Table 2. Chemical compositions of each raw material and ingredient adjuster

\begin{tabular}{cccccc}
\hline Classification & $\mathrm{CaO}$ & $\mathrm{SiO}_{2}$ & $\mathrm{Al}_{2} \mathrm{O}_{3}$ & $\mathrm{Fe}_{2} \mathrm{O}_{3}$ & $\mathrm{SO}_{3}$ \\
\hline Limestone & 45.20 & 11.15 & 2.04 & 0.81 & 0.20 \\
Converter Slag & 31.80 & 14.90 & 2.74 & 38.40 & 0.11 \\
\hline
\end{tabular}

\section{Experimental methods}

In this study, actual waste cementitious powder was first collected from 11 sites nationwide in Korea and the chemical composition of the samples was analyzed. The addition ratio of fine aggregate was estimated through comparison with Portland cement by using the SOLVER add-in in Excel using the principle of GRG (Generalized Reduced Gradient) Methods, and the model waste cementitious powder was generated. At the same time, the effect on the use of fine aggregate added to the waste cementitious powder as an alternative material for limestone was investigated. Multiple optimization for the combination of raw materials was performed to make 
recycled cement by using SOLVER add-in in EXCEL with converter slag utilizing waste cementitious powder as an alternative material for limestone[6]. Raw material adjustment factor range was LSD (Lime Saturation Degree: $\left(\mathrm{CaO}-0.7 \times \mathrm{S} \mathrm{O}_{3}\right) /\left(2.8 \mathrm{SiO}_{2}+\right.$ 1. $\left.18 \mathrm{Al}_{2} \mathrm{O}_{3}+0.65 \mathrm{Fe}_{2} \mathrm{O}_{3}\right) \times 100$ ) of 87.0, $\mathrm{SM}$ (Silica Modulus: $\left.\mathrm{SiO}_{2} /\left(\mathrm{Al}_{2} \mathrm{O}_{3}+\mathrm{Fe}_{2} \mathrm{O}_{3}\right) \times 100\right)$ of 3.0 and IM (Iron Modul: $\left.\mathrm{Al}_{2} \mathrm{O}_{3} /\left(\mathrm{Fe}_{2} \mathrm{O}_{3}\right) \times 100\right)$ of 1.10 on the basis of moderate heat cement with low LSD and high SM in order to maximize the amount of use of waste cementitious powder including large amount of $\mathrm{SiO}_{2}$ [7]. In order to determine the degree of recovery of hydration of recycled cement, in this study, TG/DTA thermal analysis, Free $\mathrm{CaO}$ measurement, and X-ray diffraction analysis were performed. These were performed at different temperatures such as $900^{\circ} \mathrm{C}, 1200^{\circ} \mathrm{C}, 1300^{\circ} \mathrm{C}, 1400^{\circ} \mathrm{C}$ and $1450^{\circ} \mathrm{C}$ in order to determine the degree of recovery of hydration at each calcination temperature. Experimental items, experimental factors and levels are shown in Tables 3 and 4 below. The manufacturing process of clinker, model cementitious powder, used in this experiments is shown in Figure 1.

Table 3. Experimental factors and levels

\begin{tabular}{ccccc}
\hline & \multirow{2}{*}{$\begin{array}{c}\text { cementitious } \\
\text { powder model } \\
(\%)\end{array}$} & $\begin{array}{c}\text { Firing } \\
\text { temperature } \\
\left(\mathrm{C}^{\mathrm{C}}\right)\end{array}$ & $\begin{array}{c}\text { Firing } \\
\text { time } \\
(\mathrm{min})\end{array}$ & $\begin{array}{c}\text { Raw } \\
\text { materlal of } \\
\text { OPC }\end{array}$ \\
\cline { 3 - 5 } & & 900 & & \\
Level & S/M 65 & 1200 & & Lime stone \\
& & 1300 & 60 & conv.slag \\
ea & 1400 & & 1 \\
\hline
\end{tabular}

Table 4. Experimental item

\begin{tabular}{|c|c|c|}
\hline \multicolumn{2}{|c|}{ Experimental Item } & Note \\
\hline Stability of clinker & X-ray diffraction & KS M 0043 \\
\hline \multirow[t]{2}{*}{ Hydration property } & $\begin{array}{c}\text { Thermal,analysis } \\
(\mathrm{TG} / \mathrm{DTA})\end{array}$ & KS M ISO 11358 \\
\hline & Free $\mathrm{CaO}$ & - \\
\hline
\end{tabular}

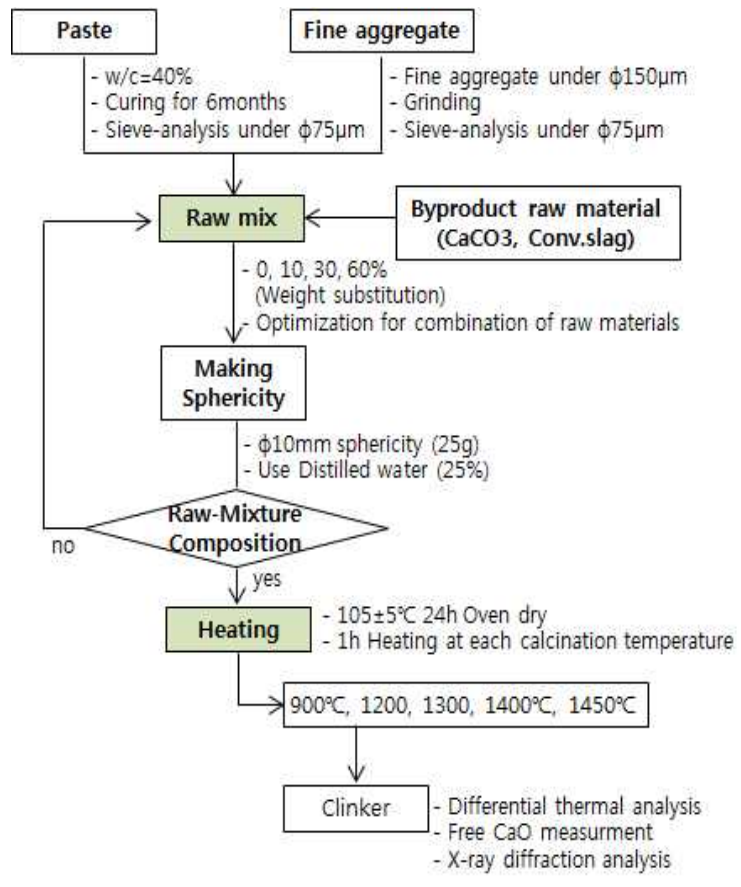

Figure 1. Flow chart of the manufacture of recycle cement model

\section{Experimental results and analysis.}

\subsection{Chemical compositions of actual waste cementitious powder.}

The results of an analysis on the chemical compositions of actual waste cementitious powder are shown in Table 5. Comparisons with the chemical composition of Portland cement are shown in Figure 2. As shown in Figure 2, chemical composition of actual waste cementitious powder had approximately 30\% more $\mathrm{SiO}_{2}$, approximately $5 \%$ more $\mathrm{Al}_{2} \mathrm{O}_{3}$, approximately $43 \%$ less $\mathrm{CaO}$ and approximately $0.6 \%$ less $\mathrm{Fe}_{2} \mathrm{O}_{3}$ compared with the levels found in Portland cement. This is thought to have been caused by the inclusion of cementitious fine aggregate which cannot be completely separated because of the similar grain size.

Through an analysis based on chemical compositions of fine aggregate in Table 1 and the chemical composition of original Portland cement in Table 6, it was found that the mean of chemical composition of actual waste cementitious powder showed the most 
similar degrees of addition of $65 \%$ of fine aggregate in all conditions to the addition ratio of fine aggregate . Despite a slight difference in the two values, all values of addition of $65 \%$ of fine aggregate are included in the actual waste cementitious powder. Chemical compositions of waste cementitious powder model with fine aggregate are shown in Table 6 .

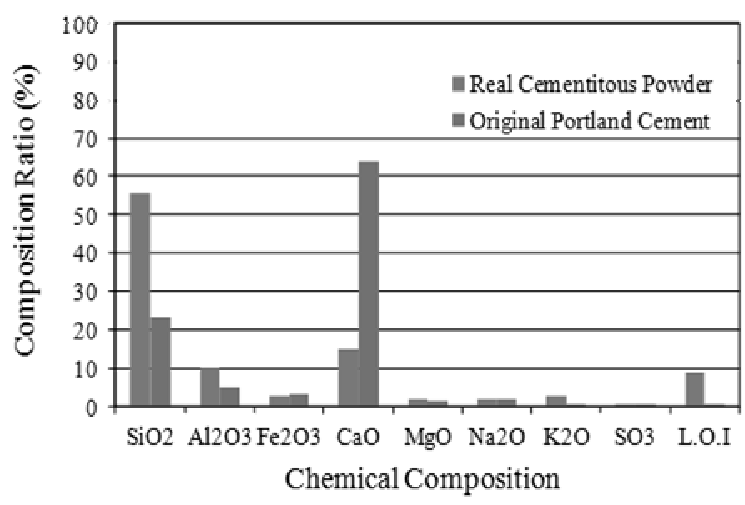

Figure 2. Comparison of chemical composition of actual waste cementitious powder and original Portland cement

Table 5. Chemical composition of actual waste cementitious powder

\begin{tabular}{cccccc}
\hline Classification & $\mathrm{CaO}$ & $\mathrm{SiO}_{2}$ & $\mathrm{Al}_{2} \mathrm{O}_{3}$ & $\mathrm{Fe}_{2} \mathrm{O}_{3}$ & $\mathrm{SO}_{3}$ \\
\hline 1 & 13.7 & 58.6 & 10.3 & 2.2 & 0.4 \\
2 & 15.2 & 56.1 & 10.3 & 2.8 & 0.5 \\
3 & 15.0 & 58.0 & 9.7 & 2.9 & 0.5 \\
4 & 15.1 & 56.2 & 10.2 & 2.7 & 0.6 \\
5 & 15.9 & 50.9 & 12.5 & 3.8 & 0.6 \\
6 & 16.6 & 54.1 & 10.3 & 3.3 & 0.5 \\
7 & 14.5 & 60.2 & 9.2 & 2.7 & 0.5 \\
8 & 14.3 & 57.6 & 10.2 & 3.2 & 0.4 \\
9 & 13.8 & 58.2 & 10.5 & 2.8 & 0.5 \\
10 & 14.9 & 56.3 & 10.3 & 3.0 & 0.4 \\
11 & 17.4 & 47.8 & 8.7 & 2.4 & 0.5 \\
Mean & 15.1 & 55.8 & 10.2 & 2.9 & 0.5 \\
Portland Cement & 63.8 & 23.1 & 5.0 & 3.0 & 0.5 \\
\hline
\end{tabular}

Table 6. Chemical composition of waste cementitious powder models

\begin{tabular}{cccccc}
\hline Classification & $\mathrm{CaO}$ & $\mathrm{SiO}_{2}$ & $\mathrm{Al}_{2} \mathrm{O}_{3}$ & $\mathrm{Fe}_{2} \mathrm{O}_{3}$ & $\mathrm{SO}_{3}$ \\
\hline Fine aggregate $50 \%$ & 24.5 & 46.7 & 8.0 & 2.3 & 0.0 \\
Fine aggregate $60 \%$ & 19.9 & 52.3 & 8.8 & 2.3 & 0.0 \\
Fine aggregate $65 \%$ & 17.6 & 55.2 & 9.2 & 2.2 & 0.0 \\
Fine aggregate 70\% & 14.2 & 59.0 & 9.6 & 2.2 & 0.0 \\
Fine aggregate 80\% & 10.6 & 63.7 & 10.5 & 2.2 & 0.0 \\
\hline
\end{tabular}

\subsection{Combination of raw materials based on the addition ratio of fine aggregates}

Combinations of raw materials were made in increments of $10 \%$ within the range of a $0 \%-90 \%$ addition ratio of fine aggregate. As shown in Figure 3 and Table 7, as the addition ratio of fine aggregate was increased, the replacement ratio of waste cementitious powder for limestone was dramatically decreased. In particular, the waste cementitious powder model with a $65 \%$ addition ratio of fine aggregate could be used as the alternative raw material for limestone at the level of $9.52 \%$. This was because it was difficult to fully synthesize to $\mathrm{C}_{3} \mathrm{~S}$ and $\mathrm{C}_{3} \mathrm{~A}$ because the amount of $\mathrm{SiO}_{2}$ is increased and ingredients of $\mathrm{CaO}$ and $\mathrm{Al}_{2} \mathrm{O}_{3}$ were decreased in waste cementitious powder due to the addition of the ingredient of fine aggregate. At the time, it was shown that the possibility of using $\mathrm{SiO}_{2}$ as an alternative for clay of quartz rather than limestone was increased. Thus, to increase the utilization of the waste cementitious powder with high added value, it is thought that the grinding technology to efficiently separate fine aggregate from cement hydrates should be developed.

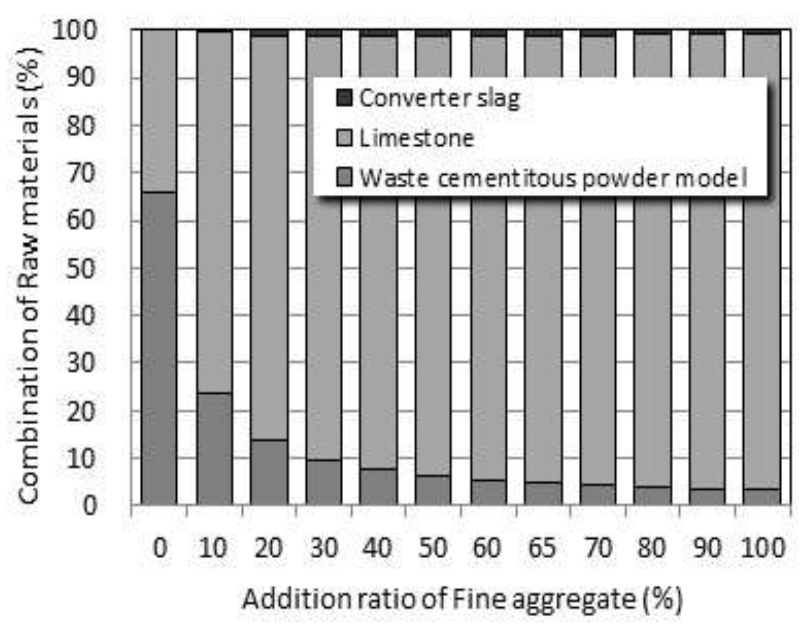

Figure 3. Combination of raw materials based on addition ratio of fine aggregate 
Table 7. Combination of raw materials based on addition ratio of fine aggregate

\begin{tabular}{ccccc}
\hline $\begin{array}{c}\text { Addition ratio } \\
\text { of fine } \\
\text { aggregate }\end{array}$ & $\begin{array}{c}\text { Waste } \\
\text { cementitious } \\
\text { powder model }\end{array}$ & Limestone & $\begin{array}{c}\text { Converter } \\
\text { slag }\end{array}$ & Ignition loss \\
\hline 0 & 81.76 & 15.78 & 2.46 & 24.82 \\
10 & 37.55 & 58.97 & 3.48 & 30.00 \\
20 & 24.37 & 71.84 & 3.78 & 31.55 \\
30 & 18.04 & 78.03 & 3.93 & 32.29 \\
40 & 14.32 & 81.66 & 4.02 & 32.73 \\
50 & 11.87 & 84.06 & 4.07 & 33.01 \\
60 & 10.14 & 86.04 & 3.82 & 33.22 \\
65 & 9.52 & 86.58 & 3.90 & 33.36 \\
70 & 8.85 & 87.01 & 4.14 & 33.37 \\
80 & 7.85 & 87.99 & 4.17 & 33.49 \\
90 & 7.05 & 88.77 & 4.18 & 33.58 \\
\hline
\end{tabular}

\subsection{Free $\mathrm{CaO}$ measurement}

Figure 4 shows the result of measurement of the contents of Free $\mathrm{CaO}$ at $900 \sim 1450^{\circ} \mathrm{C}$. As shown in the Figure, as the calcination temperature was increased, the content of free $\mathrm{CaO}$ was decreased. However, content of free $\mathrm{CaO}$ was reduced to $0.2 \sim 0.5 \%$ or almost became extinct at calcination temperatures of over $1450^{\circ} \mathrm{C}$. However, for clinker used in this study it showed more than $2 \%$, which was significantly high. In addition, Burnability (BI) was calculated as 40.96, which was somewhat lacking when compared with the levels in existing studies of 48 52. It was thought that the $\mathrm{SiO}_{2}$ included as the form of Quartz crystal caused in fine aggregate had low reactivity with $\mathrm{CaO}$.

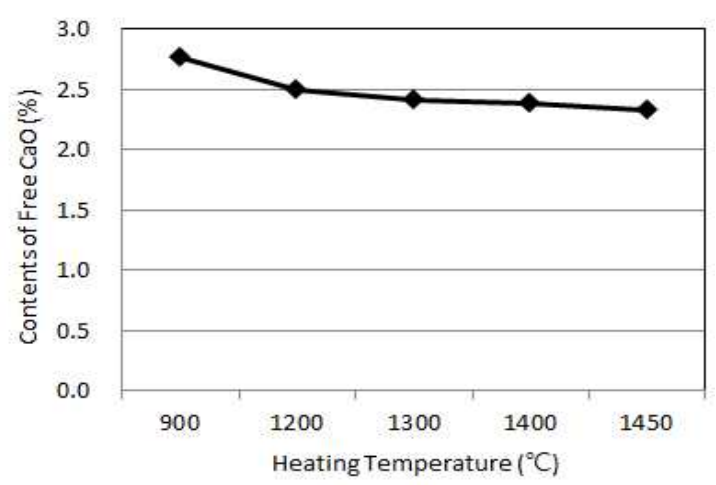

Figure 4. Free $\mathrm{CaO}$ of clinker with each firing temperature

\subsection{Differential thermal analysis.}

To determine the reactivity of combined raw materials, differential thermal analysis was conducted and the results are shown in Figure 5. The temperatures at which major reactions occurred were shown in Table 8. The formation and decomposition of compounds confirm generally suitable temperatures.

After adherent moisture of clay minerals was vaporized at $452.05^{\circ} \mathrm{C}$, endothermic peak caused by decarbonation of limestone was observed at $763.63^{\circ} \mathrm{C}$. Exothermic peak caused by $\mathrm{C}_{2} \mathrm{~S}$ was observed at $1272.9^{\circ} \mathrm{C}$. In addition, endothermic peak caused by formation of liquid phase of $\mathrm{C}_{3} \mathrm{~A}$ and $\mathrm{C}_{4} \mathrm{AF}$ was observed at $1354.74^{\circ} \mathrm{C}$. Thermal decomposition temperature of limestone was determined to be relatively low when compared with results of the study of Ahn, Ji Whan et al. The reason was that L.S.D. was set at 87, which was a low level, as moderate thermal cement was mixed with raw material. When compared with the results of the study conducted by J. A. Imlach et al., $\mathrm{C}_{3} \mathrm{~A}$ and $\mathrm{C}_{4} \mathrm{AF}$ formed liquid phase at a relatively high temperature, because it was mixed at S.M. of 3.0, a high level. In addition, $\mathrm{CaCO}_{3}$ decomposition reaction was $39.93 \%$ at $763.63^{\circ} \mathrm{C}$, which was similar to the previous study.

Table 8. Differential Thermal Analysis of waste cementitious powder model raw material

\begin{tabular}{lccc}
\hline & $\begin{array}{c}\mathrm{CaCO}_{3} \\
\text { decomposition }\end{array}$ & $\begin{array}{c}\mathrm{C}_{2} \mathrm{~S} \\
\text { formation }\end{array}$ & $\begin{array}{l}\text { Liquid } \\
\text { phase }\end{array}$ \\
\hline Temperature $\left({ }^{\circ} \mathrm{C}\right)$ & 763.63 & 1272.9 & 1354.74 \\
\hline
\end{tabular}

\subsection{X-Ray diffraction analysis.}

$\mathrm{XRD}$ pattern of clinker at each calcination temperature is shown in Figure 6. As shown in the Figure, a large amount of $\mathrm{SiO}_{2}$ and $\mathrm{CaO}$, which did not have any reactivity at $900^{\circ} \mathrm{C}$, existed, and $\beta-\mathrm{C}_{2} \mathrm{~S}$ phase, which was some linker mineral phase, appeared slightly. However, the major ingredients did not seem to be reactive yet. Despite this, it was shown that 
clinker calcinated at over $1200^{\circ} \mathrm{C}$ produced $\mathrm{C}_{3} \mathrm{~S}$ and $\beta-\mathrm{C}_{2} \mathrm{~S}$ as diffraction peaks of $\mathrm{SiO}_{2}$ and $\mathrm{CaO}$ were reduced. In the case of $\mathrm{C}_{3} \mathrm{~A}$, diffraction peaks were shown at 1300 and $1400{ }^{\circ} \mathrm{C}$, but became extinct at $1450^{\circ} \mathrm{C}$.

In general, the amount of $\mathrm{C}_{2} \mathrm{~S}$ reached a maximum at $1200^{\circ} \mathrm{C}$. As the liquid phase began to be generated at $1250^{\circ} \mathrm{C}$, the reaction of $\mathrm{C}_{2} \mathrm{~S}$ and $\mathrm{CaO}$ was facilitated so that the amount of $\mathrm{C}_{3} \mathrm{~S}$ tended to increase. However, the amount of $\mathrm{C}_{2} \mathrm{~S}$ and $\mathrm{C}_{3} \mathrm{~S}$ was constant at over $1200^{\circ} \mathrm{C}$, because the cause was thought to be the same result found in Free $\mathrm{CaO}$ analysis.

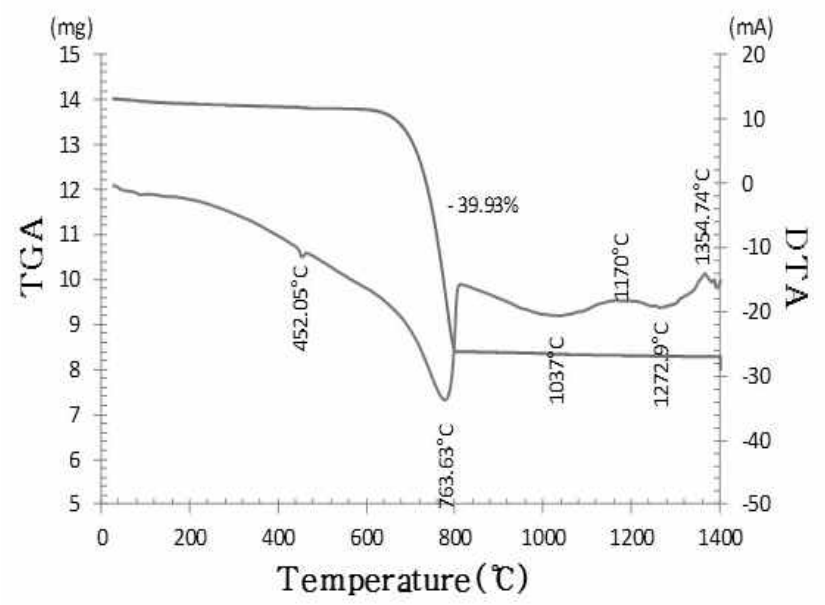

Figure 5. TG-DTA curves of raw material

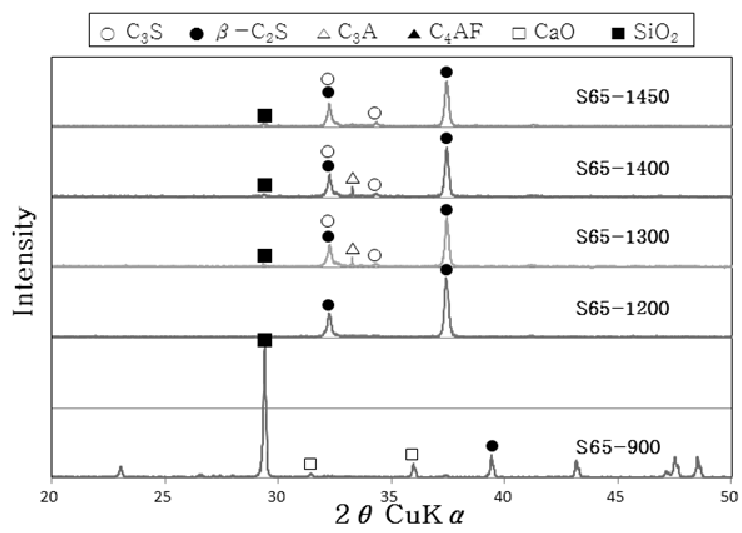

Figure 6. XRD pattern of clinker with each firing temperature

\section{Conclusions}

The following conclusions were obtained through the above experiments.

1) Through the analysis of the chemical compositions of cementitious powder of waste concrete, $\mathrm{CaO}$ and $\mathrm{SiO}_{2}$ are found to be the main ingredients, as had been shown in the existing studies. Content of $\mathrm{CaO}$ is significantly decreased but content of $\mathrm{SiO}_{2}$ is significantly increased. Mix ratio of fine aggregate and fine powder is found to be approximately $65 \%$.

2) By attempting to chemically optimize recycled cement for multi-purpose use, it is found that cement of moderate heat with values of LSD:87, SM:3, IM:1.1 can be produced. It is found that the replacement rate of cementitious powder for limestone is dramatically reduced when the mixing ratio of fine aggregate is increased.

3) In the differential thermal analysis of the composition of raw materials, exothermic peak caused by $\mathrm{C}_{2} \mathrm{~S}$ formation is observed at $1272.9^{\circ} \mathrm{C}$. Endothermic peak caused by formation of liquid phase is observed at $1354.74^{\circ} \mathrm{C}$.

4) The analysis of free $\mathrm{CaO}$ showed that the content of free $\mathrm{CaO}$ is reduced with increasing calcination temperature. However, it has a relatively low burnability of 40.96 .

5) Through $X$-ray diffraction analysis of the recycled cement, it was found that compounds composed of cement such as $\mathrm{C}_{2} \mathrm{~S}, \mathrm{C}_{3} \mathrm{~S}$ and $\mathrm{C}_{3} \mathrm{~A}$ can be synthesized. However, there is no significantly big change at $1200^{\circ} \mathrm{C}$ or higher.

The investigations described above showed that recycled cement can be utilized as an alternative raw material to limestone. However, to increase the replacement ratio, fine powder of fine aggregate should 
be efficiently separated from the waste cementitious powder.

\section{Acknowledgement}

This work was supported by the National Research Foundation of Korea(NRF) grant funded by the Korea government(MEST) (No. NFR-2013-0014286)

This research was supported by Korea Ministry of Land, Transport and Maritime Affairs through grant B01 of Construction Technology Innovation Program.

\section{References}

1. Park CW. Recycling Technology of Cementitious Powder for Completely Recycling of Concrete Waste. Journal of The Korea Institute of Building Construction. 2005 Sep;5(3):109-17.

2. Han KK. A Study on Sources of Construction Wastes and Recycling Strategy. Journal of Korea institute of Ecological Architecture and Environment. 2008 Oct;8(5):69-76.

3. Ahn JC, Oh SG, Kang BH. Characteristics of Hydration of Recycled Cement using by Product Cementitious Powder of Actual Waste Cement. Journal of Architectural Institute of Korea (structural system). 2005 Sep;21(9):121-8.

4. Choi TH. The Study on the Fire Resistance of Mortar using of Discarded EPS Powder . Journal of Architectural Institute of Korea (structural system). 2010 Dec;2010(1):399-403.

5. Oh SG. Study on Recovery of Hydration of Recycled Cement using Cementitious Powder of Waste Cement. Journal of Architectural Institute of Korea (structural system). 2002 Oct;18(10):53-60.

6. Lee SH. Study on Feed Mix Program and Growth Modelling System of Layer using Excel Solver [master's thesis]. [Sunchon (Korea)]: Sunchon National University; 2009. 42 p.

7. Ahn JW. Study on Making Paste Cementitious Powder collected from Waste Cement for Cement Materials. Journal of the Korean Ceramic Society. 2003 Jul;40(8):804-10. 